\title{
Full Ka-band High Performance InP MMIC LNA Module
}

\author{
Yu-Lung Tang, Niklas Wadefalk, Matthew A. Morgan, and Sander Weinreb \\ California Institute of Technology, Pasadena, CA 91125, USA
}

\begin{abstract}
A 0.1-um InP HEMT Ka-band LNA with high and flat gain, very low noise figure and low VSWR has been developed. Across the entire Ka-band, of $26 \mathrm{GHz}$ to $40 \mathrm{GHz}$, the MMIC LNA demonstrated associated gain of $21.9 \pm 0.9 \mathrm{~dB}$ and an average noise figure of $1.5 \mathrm{~dB}$ with a minimum of $1.3 \mathrm{~dB}$ at 34 GHz. The LNA chip was cryogenically cooled to $12 \mathrm{~K}$ where it exhibited an associated gain of $23.0 \pm 1.1 \mathrm{~dB}$ and an average noise temperature of $15.5 \mathrm{~K}$, i.e. 0.23-dB noise figure. Two LNA chips were cascaded and assembled into a module. At room temperature, the module achieved an associated gain of $37.6 \mathrm{~dB} \pm$ $1.8 \mathrm{~dB}$ and an average noise figure of $1.3 \mathrm{~dB}$. At $15 \mathrm{~K}$, the average noise temperature was improved to $11.4 \mathrm{~K}$ with $41.0 \pm$ $2.4 \mathrm{~dB}$ associated gain.
\end{abstract}

Index Terms - MMIC, cryogenic, LNA, low noise amplifier, InP-based HEMT.

\section{INTRODUCTION}

$\mathrm{Ka}$ band is a very important frequency range for radio astronomy and the wide bandwidth space communications bands of 25.5-27, 31.0-31.5, and 37-38 GHz. A high performance LNA covering the entire $\mathrm{Ka}$ band for use in future arrays is desired. In these systems, cryogenic cooling decreases the LNA noise by approximately a factor of 8 and is well worth the expense and complexity of the cooling. A cryogenically-cooled Ka-band MIC InP LNA is described in [1] and other cryogenically cooled MIC and MMIC InP LNAs over a range of frequencies from 5 to $115 \mathrm{GHz}$ are described in [2]-[5]. Some Ka-band MMIC LNA demonstrated with minimum noise figure by using GaAs [6], InP [7], and InAs/AlSb [8]

In this paper, we present design and test data for a 26-40 $\mathrm{GHz}$ InP LNA MMIC and a compact, two-MMIC LNA module which includes a built-in $30 \mathrm{~dB}$ directional coupler for calibration or test signals. The MMIC is superior to those in previous publications because of its noise and gain performance over the full waveguide band. The replication cost should be low due to the MMIC technology and simple module design.

Yu-Lung Tang is currently with TriQuint Semiconductor, Hillsboro, OR 97124 , USA.

Niklas Wadefalk is currently with the Department of Microelectronics and Nanoscience, Chalmers University of Technology, S-41296 Göteborg, Sweden.

Matthew A. Morgan is currently with National Radio Astronomy Observatory, Charlottesville, VA 22903, USA.

\section{MMIC DESIGN}

The technology used for the MMIC LNA design is Northrop Grumman 0.1- $\mu \mathrm{m}$ InP HEMT with 3-inch wafers thinned to $75 \mu \mathrm{m}$. This process features a cut-off frequency $\mathrm{f}_{\mathrm{T}}$ of $180 \mathrm{GHz}$, maximum oscillation frequency $\mathrm{f}_{\max }$ of $350 \mathrm{GHz}$ and transconductance of $950 \mathrm{mS} / \mathrm{mm}$. S-parameters of $4 \times 15$ $\mu \mathrm{m}$ transistors were measured to extract a small-signal model [9] used for MMIC design in conjunction with the Pospieszalski gate/drain temperature noise model [10]. As shown in Fig. 1, the MMIC LNA consists of three stages, each of which employs a $4 \times 15-\mu \mathrm{m}$ transistor with source inductive stub. Microstrip lines are used for matching networks and interconnection. The first stage is mainly designed for minimum noise figure while the second stage is matched partially for noise and the third stage fully for gain. With more inductive degeneration than the second and the third stages, the fist stage optimum impedances for $\mathrm{NF}_{\min }$ and $\mathrm{G}_{\max }$ are closer together. Therefore, an input matching network can be constructed to achieve minimum noise figure and simultaneously provide good input return loss. To accomplish wide-band matching, lossy matching networks are applied at the second inter-stage and output matching of the third stage. Bias is brought into the transistors through capacitively shorted stubs. The gate bias of the first stage is separated from the rest. Thus, the first stage can be independently tuned to the optimum bias of minimum noise figure. A common dc bus supplies bias voltage to all three drains.

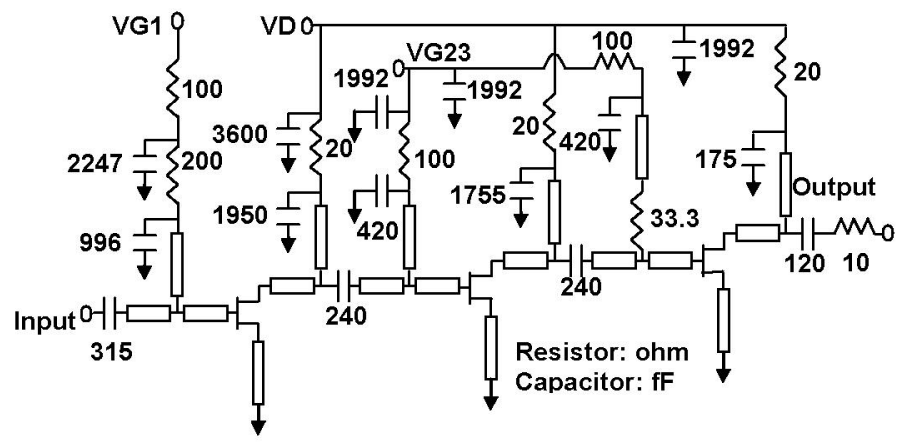

Fig. 1. Schematic diagram of Ka-band MMIC LNA 
MIM capacitors are used for dc blocking and bypass. Via holes are provided for $\mathrm{rf}$ and dc grounding. Two shunt MIM capacitors and a resistor compose the bypass circuitry. The smaller capacitor directly bypasses rf signals at the operation frequencies while a larger one following the resistor bypasses signals at lower frequencies.

The resistor acts as a damping element to suppress excess out-of-band gain and stabilize the amplifier, because InP HEMT devices inherently have high gain at low frequencies. In addition, the resistor can de-Q the bypass circuitry to eliminate unwanted resonances caused by shunt capacitors and via-hole parasitic inductance.

\section{MEASUREMENT}

Figure 2 shows a photograph of the Ka-band three-stage MMIC LNA. The chip occupies an area of $1.7 \mathrm{~mm}^{2}$ which measures $2.1 \mathrm{~mm}$ by $0.82 \mathrm{~mm}$. The chips were first tested onwafer using an Anritsu $37397 \mathrm{C}$ vector network analyzer (VNA). Input and output signals were coupled through ground-signal-ground (GSG) probes while dc voltages were supplied via a dc probe card. A short-open-load-through (SOLT) calibration was performed with a GGB CS-5 calibration substrate, placing the reference plane at the probe tips. The measurement was made at $\mathrm{VD}=0.7 \mathrm{~V}$ and a total current of $20.0 \mathrm{~mA}$, corresponding to a dc power consumption of $14 \mathrm{~mW}$. The measured s-parameters at Ka-band frequencies are shown in Fig. 3. From $26 \mathrm{GHz}$ to $40 \mathrm{GHz}$, the amplifier achieves $25.0-\mathrm{dB}$ gain with $1.9-\mathrm{dB}$ flatness. The flatness of the amplifier is defined by

$$
\text { Flatness }(\mathrm{dB})=(\text { Gain, } \max -\text { Gain, } \min ) / 2
$$

Both input and output return loss are better than $10.0 \mathrm{~dB}$ across the entire Ka-band. Near the center of the band at 34 $\mathrm{GHz}$, the gain is $26 \mathrm{~dB}$ with return loss better than $20.0 \mathrm{~dB}$. Well-matched ports can eliminate the need for off-chip matching networks and thereby reduce system complexity. Fig. 4 shows the results from $0.5 \mathrm{GHz}$ to $65 \mathrm{GHz}$. Within this frequency range, the $\mathrm{K}$ factor is greater than 1 assuring unconditional stability.

The noise performance was characterized by the Y-factor method using an Agilent N8975A noise figure meter (NFM) with a 12-dB excess noise ratio (ENR) noise diode (HP R347B). The noise diode was followed by a 6-dB attenuator to improve the difference in source impedance between onand off-states and to reduce ENR as well. The N8975A can only detect signals below $26 \mathrm{GHz}$. Thus, a mixer (Spacek Labs Rka-14) was used to convert Ka-band signals down to $30 \mathrm{MHz}$. Noise figure at room temperature $(290 \mathrm{~K})$ was measured as the amplifier was biased for minimum noise figure at VD $=0.8 \mathrm{~V}$ and a total current of $20.0 \mathrm{~mA}$.

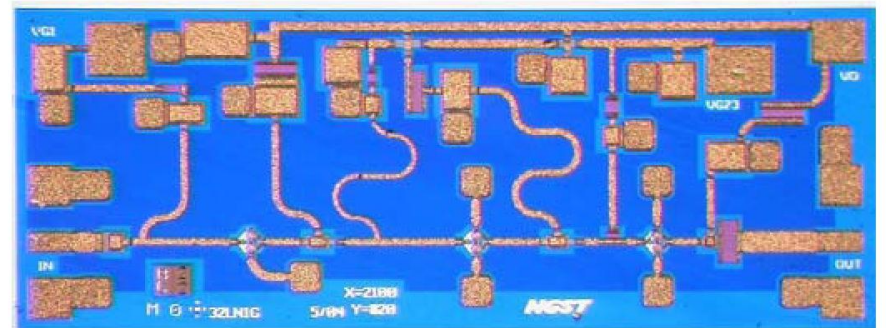

Fig. 2. Photograph of Ka-band MMIC LNA. The compact die measures $2.1 \mathrm{~mm}$ by $0.82 \mathrm{~mm}$ with a thickness of $75 \mu \mathrm{m}$.

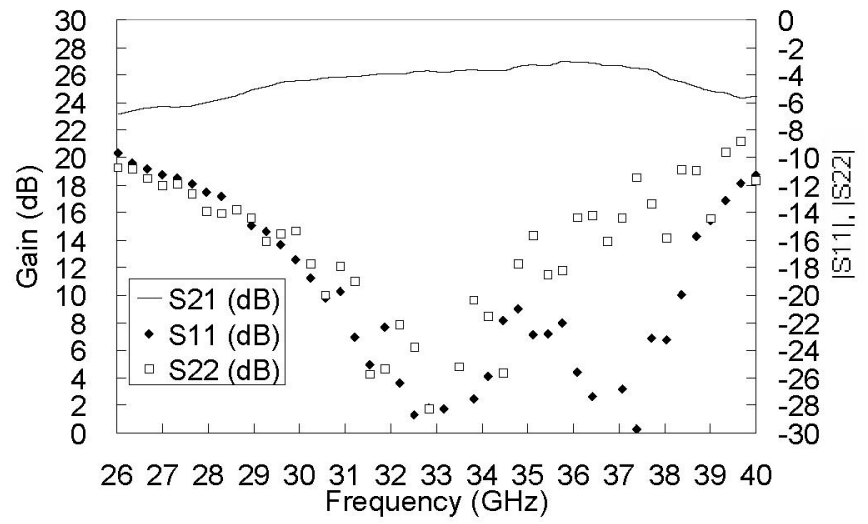

Fig. 3. Measured s-parameters at Ka-band frequencies.

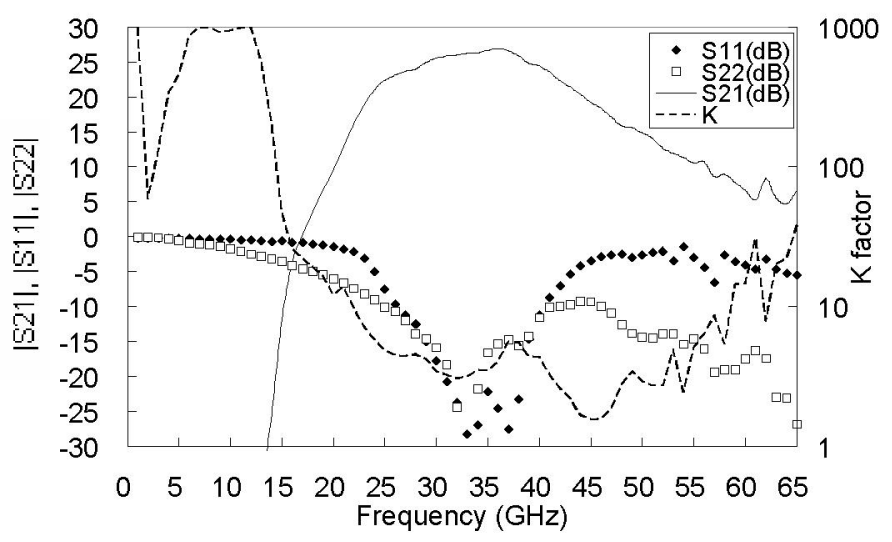

Fig. 4. Measured s-parameters from $0.5 \mathrm{GHz}$ to $60 \mathrm{GHz}$.

Thus, a mixer (Spacek Labs Rka-14) was used to convert Ka-band signals down to IF. Noise figure at room temperature $(290 \mathrm{~K})$ was measured as the amplifier was biased for minimum noise figure at $\mathrm{VD}=0.8 \mathrm{~V}$ and a total current of $20.0 \mathrm{~mA}$. Figure 5 shows the measured noise temperature and associated gain. From $26 \mathrm{GHz}$ to $40 \mathrm{GHz}$, the average noise temperature is $123.5 \mathrm{~K}$, corresponding to $1.5 \mathrm{~dB}$ noise figure. Noise temperature is converted into noise figure by using

$$
\text { Noise Figure }(d B)=10 \log \left[1+\frac{\text { Noise Temp }}{290}\right]
$$

The associated gain is $21.9 \mathrm{~dB}$ with $0.9-\mathrm{dB}$ flatness. Noise figure reaches a minimum of $1.3 \mathrm{~dB}$ at $34 \mathrm{GHz}$ with 
associated gain of $22.5 \mathrm{~dB}$. Overall in Ka-band, the noise figure is below $1.9 \mathrm{~dB}$ and associated gain higher than $21.0 \mathrm{~dB}$. The slight ripple in measured noise temperature is due to mismatch between waveguide components in the test setup. Mismatch could be reduced with the addition of an isolator or attenuator.

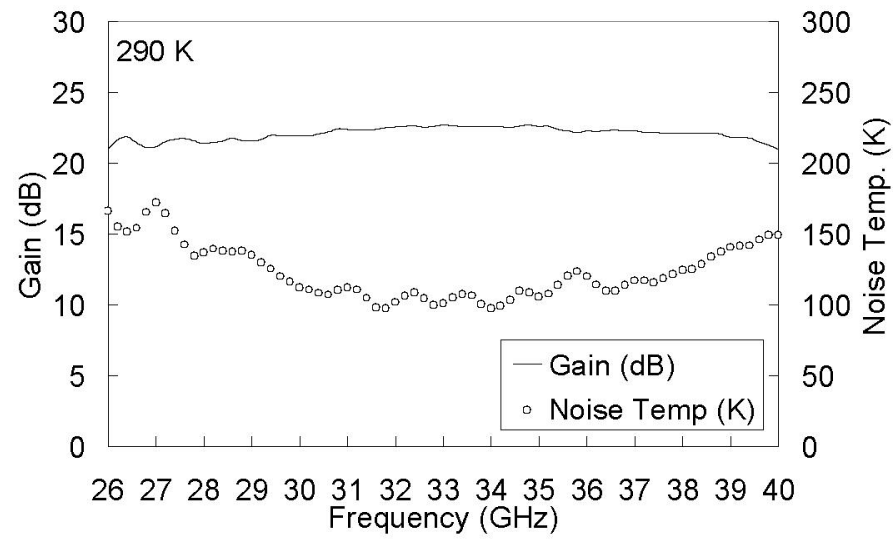

Fig. 5. Measured noise temperature and associated gain of the MMIC LNA, from $26 \mathrm{GHz}$ to $40 \mathrm{GHz}$, at $290 \mathrm{~K}$.

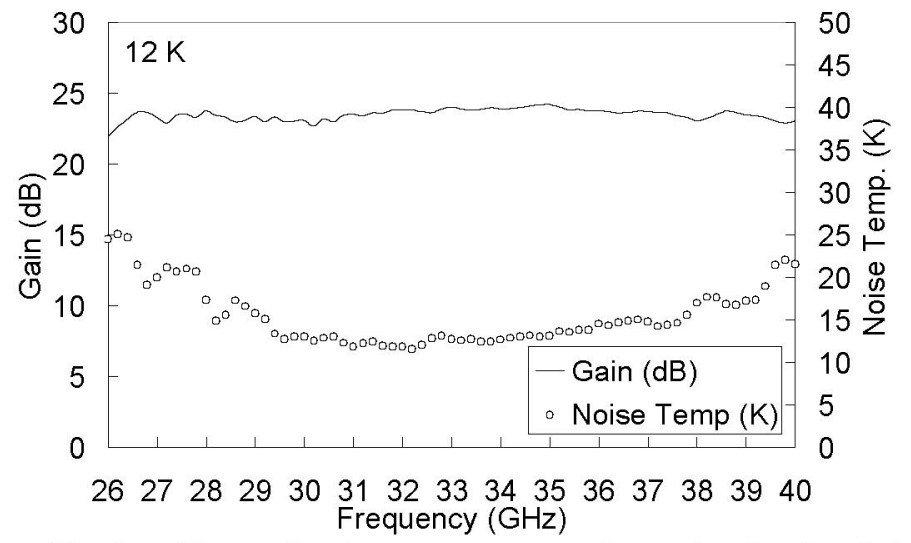

Fig. 6. Measured noise temperature and associated gain of the MMIC LNA, from $26 \mathrm{GHz}$ to $40 \mathrm{GHz}$, at $12 \mathrm{~K}$.

The noise performance was then measured with the amplifier operating cryogenically. As shown in Fig. 6, the noise temperature can be greatly reduced to an average of 15.5 $\mathrm{K}$ by cooling the amplifier down to an ambient temperature of $12 \mathrm{~K}$ and adjusting the bias to $\mathrm{VD}=0.7 \mathrm{~V}$ with a total current of $8.5 \mathrm{~mA}$. The associated gain is $23.0 \mathrm{~dB}$ with $1.1-\mathrm{dB}$ flatness. The minimum noise figure occurs at the center of the band. At $34 \mathrm{GHz}$, noise temperature reaches a minimum of $11.8 \mathrm{~K}$, equivalent to a noise figure of $0.17 \mathrm{~dB}$ using (2).

\section{KA-BAND LNA MODULE}

For a system that calls for higher gain, a multi-chip module is required. Such high gain would be difficult to achieve in a single chip, as well as being risky in terms of stability, so a two-chip module is preferable. The LNA module consists of two LNA chips, a fixed attenuation pad, transition probes, a printed circuit board (PCB) and a 30-dB coupler terminated with a tapered load. As shown in Fig. 7, the module has a WR-28 input, a coax output, a coax calibration port and a 9pin bias port. As shown in Fig. 8 of the module interior, input rf signals are fed into a WR-28 waveguide and coupled to a waveguide-to-microstrip transition, followed by two LNA chips separated by a $6-\mathrm{dB}$ attenuation pad. The attenuation pad is used to isolate the two LNAs from each other. The 30$\mathrm{dB}$ waveguide coupler is a multi-aperture design [11] and is used as a calibration port for injecting signals from an external noise source. On the output, if signals come out of a coax connector via a microstrip-to-coax transition [12]. Bias is supplied to the chips through a PCB with diagnostic and protection circuitry. Chip capacitors are mounted and wirebonded onto the chassis to bypass signals in the $\mathrm{MHz}$ range. The transition probes and attenuation pad are fabricated on alumina substrates using a thin-film process. The dimension of the cavity where chips reside is carefully designed to suppress unwanted waveguide modes. The module measures $5.1 \mathrm{~cm} \times 4.1 \mathrm{~cm} \times 2.0 \mathrm{~cm}$. The module was tested using the N8975A NFM from $26 \mathrm{GHz}$ to $40 \mathrm{GHz}$. Both noise temperature and associated gain were characterized at room and cryogenic ambient temperatures.

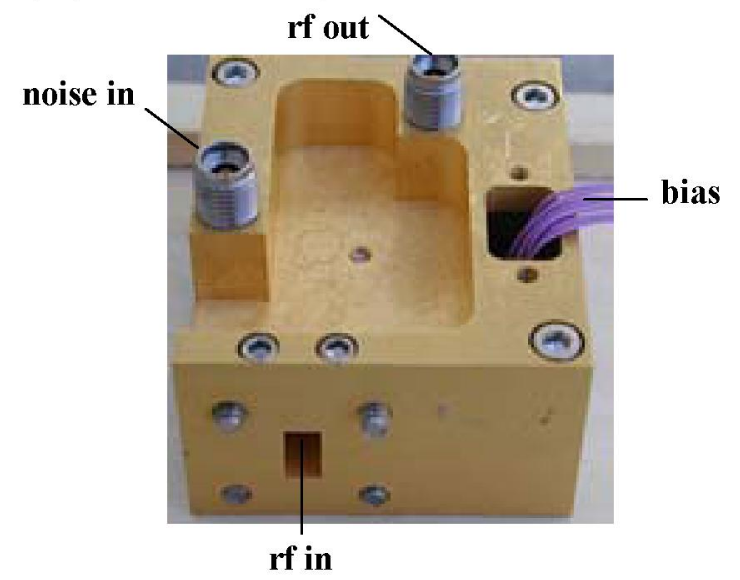

Fig. 7. Photograph of the Ka-band LNA module, WR-28 input, coax output, and an additional coax port for injecting calibration noise signals.

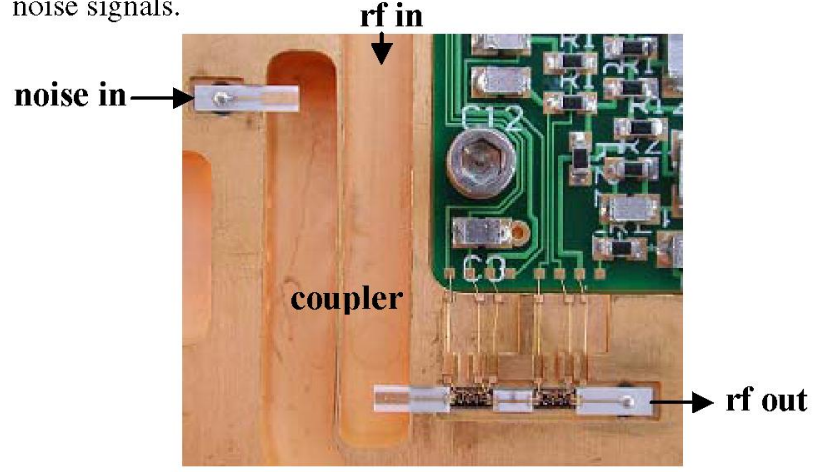

Fig. 8. Photograph of the module interior. Two chips are cascaded with a $6-\mathrm{dB}$ attenuation pad inserted in between the chips. 


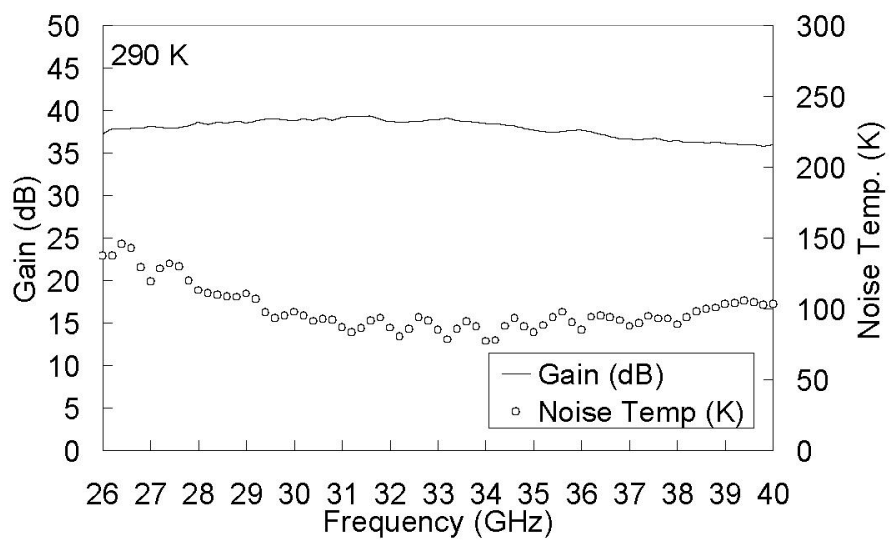

Fig. 9. Measured noise temperature and associated gain of the LNA module, from $26 \mathrm{GHz}$ to $40 \mathrm{GHz}$, at $290 \mathrm{~K}$.

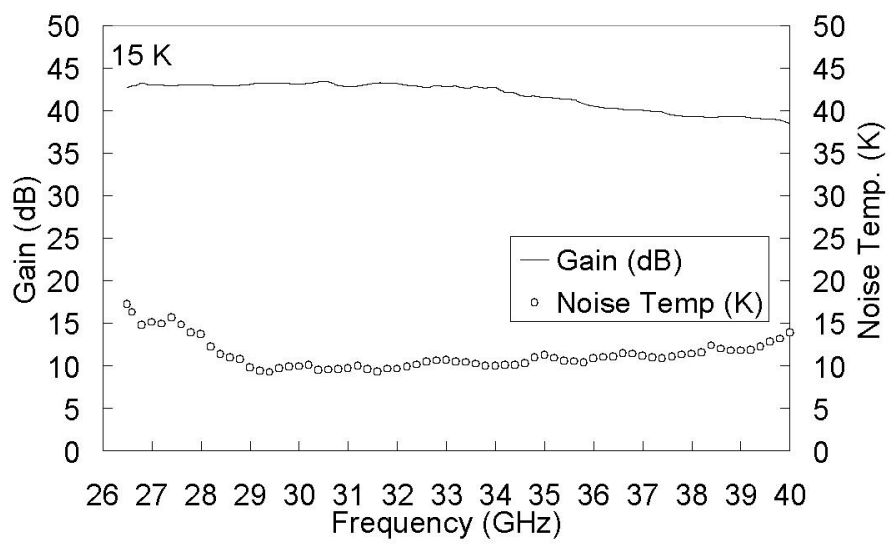

Fig. 10. Measured noise temperature and associated gain of the LNA module, from $26 \mathrm{GHz}$ to $40 \mathrm{GHz}$, at $15 \mathrm{~K}$.

As shown in Fig. 9, the module at $290 \mathrm{~K}$ can achieve an associated gain of $37.6 \mathrm{~dB}$ with $1.8 \mathrm{~dB}$ flatness for the full $\mathrm{Ka}$ band, and an average noise temperature of $99.5 \mathrm{~K}$, equivalent to $1.3 \mathrm{~dB}$ noise figure. As the module is cooled to $15 \mathrm{~K}$, average noise temperature is reduced to $11.4 \mathrm{~K}$ with $41.0-\mathrm{dB}$ gain and 2.4-dB flatness. At $34 \mathrm{GHz}$, the module reaches a minimum noise temperature of $9.3 \mathrm{~K}$ with $43.2-\mathrm{dB}$ gain.

\section{CONCLUSION}

A Ka-band MMIC LNA has been developed and achieves high performance over the entire band. The MMIC chip demonstrates flat gain response, low return loss and low noise temperature. By using this MMIC design, a cryogenic LNA module consisting of two chips has been successfully developed. At $300 \mathrm{~K}$ the module provides $37.6-\mathrm{dB}$ gain and $1.3-\mathrm{dB}$ noise figure and at $15 \mathrm{~K}$ the module has $43.2 \mathrm{~dB}$ gain and $9.3 \mathrm{~K}$ noise temperature at $34 \mathrm{GHz}$.

\section{REFERENCES}

[1] J. J. Bautista, J. G. Bowen, J. E. Fernandez, Z. Fujiwara, J. Loreman, S. Petty, J. L. Prater, R. Grundbacher, R. Lai, M. Nishimoto, M. R. Murti, and J. Laskar, "Cryogenic, X-band and Ka-band InP HEMT based LNAs for the Deep Space Network," Proc. IEEE Aerospace Conf., vol. 2, pp. 2/829-2/842, 2001.

[2] N. Wadefalk, A. Mellberg, I. Angelov, M. E. Barsky, S. Bui, E. Choumas, R. W. Grundbacher, E. L. Kollberg, R. Lai, N. Rorsman, P. Starski, J. Stenarson, D. C. Streit, and H. Zirath, "Cryogenic wide-band ultra-low-noise IF amplifiers operating at ultra-low DC power," IEEE Trans. Microwave Theory \& Tech., vol. 51, no. 6, pp. 1705-1711, June 2003.

[3] S. Weinreb, R. Lai, N. Erickson, T. Gaier, and J. Wielgus, "Wband InP wideband MMIC LNA with $30 \mathrm{~K}$ noise temperature," 1999 IEEE MTT-S Int. Microwave Symp. Dig., vol. 1, pp. 101104, June 1999.

[4] I. Lopez-Fernandez, J. D. G. Puyol, O. J. Homan, and A. B. Cancio, "Low noise cryogenic X-band amplifier using wetetched, hydrogen passivated InP HEMT devices," IEEE Microwave and Guided Wave Letters, vol. 9, pp. 413-415, October 1999.

[5] N. R. Erickson, R. M. Grosslein, R. B. Erickson, and S. Weinreb, "A cryogenic focal plane array for 85-115 GHz using MMIC preamplifiers," 1999 IEEE MTT-S Int. Microwave Symp. Dig., vol. 1, pp. 251-254, June 1999.

[6] S. Fujimoto, T. Katoh, T. Ishida, T. Oku, Y. Sasaki, T. Ishikawa and Y. Mitsui, "Ka-band ultra low noise MMIC amplifier using pseudomorphic HEMTs," 1997 IEEE MTT-S Int. Microwave Symp. Dig., vol. 1, pp. 17-20, June 1997.

[7] C. Pobanz, M. Matloubian, L. Nguyen, M. Case, M. Hu, M. Lui, C. Hooper, and P. Janke, "A high gain, low power MMIC LNA for Ka-band using InP HEMTs," 1999 IEEE Radio Frequency Integrated Circuits Symp, pp. 149-152, June 1999.

[8] J. B. Hacker, J. Bergman, G. Nagy, G. Sullivan, C. Kadow, H Lin, A. C. Gossard, M. Rodwell, and B. Brar, "An ultra-low power InAs/AlSb HEMT Ka-band low-noise amplifier," 2004 IEEE Microwave And Wireless Components Letters, vol. 14, no. 4, pp. 156-158, April 2004.

[9] N. Rorsman, M. Garcia, C. Karlsson, and H. Zirath, ”Accurate small-signal modeling of HFETs for millimeter-wave applications," IEEE Trans. Microwave Theory \& Tech., vol. 44, pp. 432-437, March 1996.

[10] M. W. Pospieszalski, "Modeling of noise parameters of MESFETs and MODFETs and their frequency and temperature dependence," IEEE Trans. Microwave Theory \& Tech., vol. 37, pp. 1340-1350, September 1989.

[11] N. Erickson, "High performance dual directional couplers for near-mm wavelengths," 2001 IEEE Microwave And Wireless Components Letters, vol. 11, no. 5, pp. 205-207, May 2001.

[12] M. Morgan and S. Weinreb, "A millimeter-wave perpendicular coax-to-microstrip transition," 2002 IEEE MTT-S Int. Microwave Symp. Dig., pp. 817-820, Seattle, WA, June 2002. 